\title{
Probabilistic calibration of a Greenland Ice Sheet model using spatially resolved synthetic observations: toward projections of ice mass loss with uncertainties
}

\author{
W. Chang ${ }^{1}$, P. J. Applegate ${ }^{2}$, M. Haran ${ }^{1}$, and K. Keller ${ }^{3}$ \\ ${ }^{1}$ Department of Statistics, University of Chicago, Chicago, IL 60637, USA \\ ${ }^{2}$ Earth and Environmental Systems Institute, Pennsylvania State University, University Park, PA 16802, USA \\ ${ }^{3}$ Department of Geosciences, Pennsylvania State University, University Park, PA 16802, USA
}

Correspondence to: W. Chang (wonchang@psu.edu)

Received: 22 February 2014 - Published in Geosci. Model Dev. Discuss.: 25 March 2014

Revised: 29 July 2014 - Accepted: 29 July 2014 - Published: 5 September 2014

\begin{abstract}
Computer models of ice sheet behavior are important tools for projecting future sea level rise. The simulated modern ice sheets generated by these models differ markedly as input parameters are varied. To ensure accurate ice sheet mass loss projections, these parameters must be constrained using observational data. Which model parameter combinations make sense, given observations? Our method assigns probabilities to parameter combinations based on how well the model reproduces the Greenland Ice Sheet profile. We improve on the previous state of the art by accounting for spatial information and by carefully sampling the full range of realistic parameter combinations, using statistically rigorous methods. Specifically, we estimate the joint posterior probability density function of model parameters using Gaussian process-based emulation and calibration. This method is an important step toward calibrated probabilistic projections of ice sheet contributions to sea level rise, in that it uses data-model fusion to learn about parameter values. This information can, in turn, be used to make projections while taking into account various sources of uncertainty, including parametric uncertainty, data-model discrepancy, and spatial correlation in the error structure. We demonstrate the utility of our method using a perfect model experiment, which shows that many different parameter combinations can generate similar modern ice sheet profiles. This result suggests that the large divergence of projections from different ice sheet models is partly due to parametric uncertainty. Moreover, our method enables insight into ice sheet processes represented by parameter interactions in the model.
\end{abstract}

\section{Introduction}

Accurate projections of future sea level rise are important for present-day adaptation decisions. Global mean sea level has risen $0.2-0.3 \mathrm{~m}$ over the last $2-3$ centuries (e.g., Church and White, 2006; Jevrejeva et al., 2008), and this rise is expected to continue in the future (Meehl et al., 2007; Alexander et al., 2013; Edwards et al., 2014a, b). A significant fraction of world population and built infrastructure lies near presentday sea level, and these people and resources are at risk from sea level rise. Projections of sea level rise with sound characterization of the associated uncertainties can inform the design of risk management strategies (e.g., Lempert et al., 2012).

Here, we focus on the Greenland Ice Sheet component of future sea level rise, as estimated by ice sheet models. Enhanced mass loss from the Greenland Ice Sheet is just one component of overall sea level rise, which also includes contributions from the Antarctic ice sheets, small glaciers, thermal expansion of ocean water, and the transfer of water stored on land to the oceans. However, the Greenland Ice Sheet is a large potential contributor to sea level rise, and also a highly uncertain one; if this ice sheet were to melt completely, sea level would rise by about $7 \mathrm{~m}$ (Bamber et al., 2001, 2013; Lemke et al., 2007), and both the rate of ice loss and its final magnitude are uncertain (Lenton et al., 2008). Ice sheet models provide internally consistent representations of the processes that are important to the growth and decay of ice sheets. Although imperfect, such models have been the focus of intense development efforts since the 
fourth Intergovernmental Panel on Climate Change assessment report (e.g., Bindschadler et al., 2013; Shannon et al., 2013; Edwards et al., 2014a).

To yield accurate projections, ice sheet models must be started from an initial condition that resembles the real ice sheet as closely as possible, both in terms of the spatial distribution and flow of ice and the temperature distribution within the ice body. Ice flow is driven primarily by thickness and surface slope (e.g., Alley et al., 2010), and warm ice deforms more easily than cold ice. Similarly, the melt rate of a patch of the ice sheet's surface is strongly sensitive to its elevation (Born and Nisancioglu, 2012). Thus, errors in the initial condition used for ice sheet model projections will lead to inaccuracies in simulated future ice distributions and sea level rise contributions. In practice, all models include simplifications that also affect projection accuracy (e.g., Kirchner et al., 2011), perhaps more than initial condition errors. However, matching the modern ice sheet is a frequently recurring theme in the literature (e.g., Ritz et al., 1997; Greve, 1997; Huybrechts, 2002; Stone et al., 2010; Greve et al., 2011; Pollard and DeConto, 2012).

The initial condition used in ice sheet models is a function of input parameter values, as well as the spin-up method. Because the thermal field within the ice sheet is incompletely known, most modeling studies perform an initialization to bring the simulated ice sheet to a state that is consistent with the present-day climatology (e.g., Stone et al., 2010), climate model output (e.g., Fyke et al., 2011), or climate history estimated from ice cores (e.g., Applegate et al., 2012). Most studies allow the simulated ice sheet's surface topography to evolve during the spin-up period; thus, the estimated initial condition usually does not exactly match the observed ice sheet topography (Bamber et al., 2001, 2013). For example, many studies obtain a simulated modern Greenland Ice Sheet that is larger than expected (e.g., Heimbach and Bugnion, 2009; Stone et al., 2010; Robinson et al., 2010; Vizcaino et al., 2010; Greve et al., 2011; cf. Bamber et al., 2001, 2013). Ice sheet models have many uncertain parameters that affect the softness of the ice, the speed of basal sliding, and the intensity of surface melting, among other processes (Ritz et al., 1997; Hebeler et al., 2008; Stone et al., 2010; Fitzgerald et al., 2012; Applegate et al., 2012). Adjusting these parameters changes the simulated modern ice sheet (Stone et al., 2010; Applegate et al., 2012).

Despite the importance of achieving a good match between ice sheet model output and the present-day ice geometry, it remains unclear how to use data on the modern ice sheet to assess the relative plausibility of different model runs in cases where the modeled ice sheet surface topography can evolve freely. The root mean squared error (RMSE) is sometimes used for this purpose (e.g., Greve and Otsu, 2007; Stone et al., 2010). However, it is unclear how to translate the RMSE values from a set of model runs into probabilistic projections of ice volume change, as required for sea level studies. Using a probability model that accounts for various uncertainties, as we do here, helps overcome this limitation. Recent work by McNeall et al. (2013) and Gladstone et al. (2012) partly addresses the challenge of identifying appropriate parameter combinations, given observations and a freely evolving ice sheet model. McNeall et al. (2013) trained a statistical emulator (e.g., Sacks et al., 1989; Kennedy and O'Hagan, 2001) to relate input parameter combinations to highly aggregated metrics describing the Greenland Ice Sheet's geometry (volume, area, and maximum thickness; Ritz et al., 1997; Stone et al., 2010), using a previously published ensemble of ice sheet model runs (Stone et al., 2010). The work of McNeall et al. (2013) is groundbreaking in its application of a computationally efficient statistical emulator to an ice sheet model, allowing estimation of model output at many more design points than would have been possible with just the model itself. However, the highly aggregated metrics used by McNeall et al. (2013) neglect information on the spatial distribution of ice, which might further limit the parameter combinations that agree well with the observed geometry of the modern ice sheet. Moreover, their calibration approach is based on "historical mapping" and does not provide probabilistic projections. Gladstone et al. (2012) proposed a simple, but statistically robust, probabilistic approach for calibrating a flowline model of Pine Island Glacier in West Antarctica, but their approach is applicable only when the ice flow model is computationally cheap and the observational data include only a small number of observations.

A second challenge involves characterizing the effects of input parameter choice on the agreement between modeled and observed ice sheets. In an ensemble of Greenland Ice Sheet model runs carried out by Applegate et al. (2012; described below), the parameter combinations that agree well with the modern ice sheet's volume are widely distributed over parameter space, with no easily discernable structure. This result may arise from un-characterized interactions among the model parameters. This outcome also has strong implications for model projections of sea level rise from the ice sheet in that the model runs that agree well with the modern volume constraint give widely diverging sea level rise projections (Applegate et al., 2012).

Finally, estimates of future sea level rise require projections of ice volume change with well-characterized uncertainties. Perturbed-parameter ensembles (e.g., Stone et al., 2010; Applegate et al., 2012; Edwards et al., 2014a) represent an important step toward this goal, but the relatively small number of model runs that can be performed in a reasonable time (usually $10^{2}-10^{3}$; Stone et al., 2010; Applegate et al., 2012) are insufficient to fully explore model parameter space. As McNeall et al. (2013) demonstrate, statistical emulators help overcome this dimensionality problem; however, some method for assigning plausibility scores to the emulator output is also needed. In a slightly different but relevant context, Little et al. (2013) and Edwards et al. (2014b) use Bayesian model averaging to assign scores to model runs in 
perturbed-parameter ensembles, but the scores in these methods are essentially based on RMSE or low-dimensional summaries of model output and therefore do not fully account for the spatial information in ice model output.

Here, we address these challenges using a Bayesian framework that combines data, models, and prior beliefs about model input parameter values. Like McNeall et al. (2013), we train an emulator on an ensemble of ice sheet model runs. However, we build on their work by using an explicit likelihood function, and by incorporating information from a north-south profile of average ice thicknesses. Specifically, we use a Gaussian process emulator to estimate the first 10 principal components of the zonal mean ice thickness profile, following a recent climate model calibration study (Chang et al., 2014). Further, we perform a perfect model experiment to investigate the interactions between input parameters. Our approach recovers the correct parameter values and projected ice volume changes from "assumed-true" model realizations, and the multidimensional probability density function displays expected physical interactions (Sect. 1.2, below). These interactions were not evident from the simple analysis employed by Applegate et al. (2012, their Fig. 1).

The above paragraphs discuss the case in which the ice sheet model is free to evolve to the state that is most consistent with the selected parameter combination, the bedrock topography, and the climate (whether steady or varying). In such studies, parameters such as the basal sliding coefficient are held constant over the geographic area of the ice sheet. However, a number of recent studies (e.g., Gillet-Chaulet et al., 2012; Quiquet et al., 2012; Goelzer et al., 2013; Shannon et al., 2013; Edwards et al., 2014b) have used an alternative approach in which the spatially distributed basal sliding coefficients and/or surface mass balance fields are tuned so that the ice sheet model matches the observed modern geometry. This approach has several advantages; the simulated modern ice sheet is guaranteed to match the observed modern one, and the estimated basal sliding coefficients vary spatially, as is almost certainly the case for the real ice sheet. However, such studies are silent on interactions between the parameters which we investigate here.

The paper proceeds as follows. In the remainder of the Introduction, we describe the ensemble that we use to train the emulator. In Sect. 2, we outline our method for using a Gaussian process emulator to estimate the principal components of the zonally averaged ice thicknesses and the setup of our perfect model experiment. Section 3 presents the results of the perfect model experiment. In Sect. 4, we conclude by pointing out the implications of our work, as well as its limitations and potential directions for future research.

\subsection{The ensemble}

We train our emulator with a 100-member perturbedparameter ensemble described in Applegate et al. (2012). This ensemble uses the three-dimensional ice sheet model

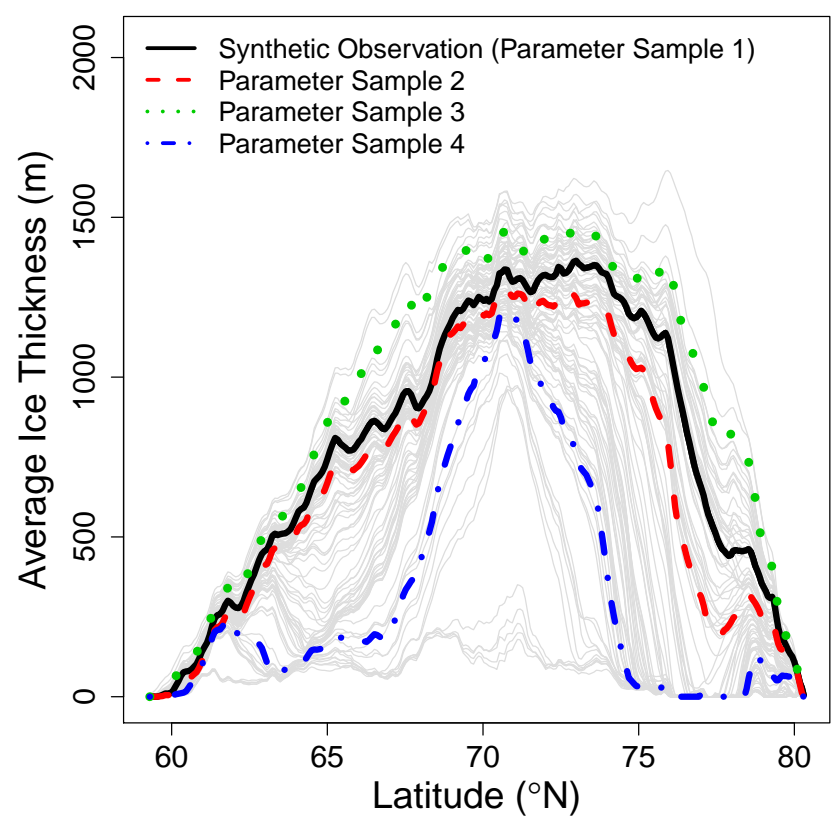

Figure 1. Profiles of zonal mean ice thicknesses from evaluations of the ice sheet model SICOPOLIS (Greve, 1997; Greve et al., 2011; Applegate et al., 2012). The solid black curve represents model run \#67 from Applegate et al. (2012), which we take to be the synthetic truth for our perfect model experiments. The other curves represent examples of model runs used to construct the emulator: one run produces a zonal mean ice thickness curve similar to the synthetic observations (dashed red curve), another is generally too thick (dotted green curve), and a third is generally too thin (dot-dashed blue curve). As expected, our probability model assigns a greater posterior probability to the model run represented by the red curve than to the model runs represented by the blue and green curves. All the other model runs from Applegate et al. (2012) that are not mentioned above are represented as grey curves.

SImulation COde for POLythermal Ice Sheets (SICOPOLIS; Greve, 1997; Greve et al., 2011). Each model run spans the period from 125000 years ago $(125 \mathrm{ka} \mathrm{BP})$ to $3500 \mathrm{yrCE}$, driven by surface temperature and sea level histories derived from geologic data (Imbrie et al., 1984; Dansgaard et al., 1993; Johnsen et al., 1997) and forced into the future with an asymptotic warming to $\sim 5^{\circ} \mathrm{C}$ above present values. SICOPOLIS is a shallow ice-approximation model, meaning that it neglects longitudinal stresses within the ice body (Kirchner et al., 2011). Like most ice sheet models, it also includes many simplifications in calculating the surface mass balance, notably through its use of the positive degree-day method for relating surface temperatures to melting (Braithwaite, 1995; Calov and Greve, 2005; van der Berg et al., 2011). These simplifications improve SICOPOLIS' computational efficiency relative to higher-order or fullStokes models (e.g., Seddik et al., 2012), allowing it to be run repeatedly over $10^{5} \mathrm{yr}$ time scales. 
The parameter combinations in the Applegate et al. (2012) ensemble were chosen by Latin hypercube sampling (McKay et al., 1979), following the earlier work of Stone et al. (2010). Latin hypercube sampling distributes points throughout parameter space more efficiently than Monte Carlo methods (Urban and Fricker, 2010). In their experiment, Applegate et al. (2012) varied the ice flow enhancement factor, the ice and snow positive degree-day factors, the geothermal heat flux, and the basal sliding factor (Ritz et al., 1997; cf. Stone et al., 2010; Fitzgerald et al., 2012). These parameters control the softness of ice, the rapidity with which the ice sheet's surface lowers at a given temperature, the amount of heat that enters the base of the ice sheet, and the speed of sliding at a given stress (see Applegate et al., 2012, for an explanation of how each parameter affects model behavior).

McNeall et al. (2013) trained their emulator using a perturbed-parameter ensemble of ice sheet model runs published by Stone et al. (2010). Key differences between the Applegate et al. (2012) ensemble and the Stone et al. (2010) ensemble involve the parameters varied in the ensembles and the processes included in the simulations. Stone et al. (2010) varied the lapse rate instead of the basal sliding factor adjusted by Applegate et al. (2012). The model used by Stone et al. (2010; Glimmer v. 1.0.4; see Rutt et al., 2009) neglects basal sliding, a process included in the SICOPOLIS runs presented by Applegate et al. (2012).

The results presented by Applegate et al. (2012) suggest that widely diverging ice sheet model parameter values yield comparable modern ice sheets, but substantially different sea level rise projections. Applegate et al. (2012) assessed the plausibility of their model runs by comparing the simulated ice volumes in 2005 to the estimated modern ice volume (Bamber et al., 2001; Lemke et al., 2007); those runs that yielded modern ice volumes within $10 \%$ of the estimated value were kept. These plausible runs yielded a range of future sea level rise projections that was $\sim 75 \%$ of the median estimate.

Moreover, the parameter combinations that agree well with the modern ice volume constraint are widely distributed over parameter space. With the exception of the ice positive degree-day factor, where only values less than $\sim 15 \mathrm{~mm}$ day ${ }^{-1}{ }^{\circ} \mathrm{C}^{-1}$ satisfy the ice volume constraint, no pattern emerges from the distribution of the successful runs through parameter space. McNeall et al. (2013) make a similar point using their own results. Statistically, this inability to learn about the plausibility of various parameter combinations given observations is termed an "identifiability problem".

\subsection{Expected interactions among model input parameters}

The apparently structureless distribution of successful runs through parameter space (Applegate et al., 2012, their Fig. 1) may stem from interactions among the parameters. The parameters can be loosely grouped into those that control the ice sheet's surface mass balance (the ice and snow positive degree-day factors) and those that control ice movement (the ice flow enhancement factor, the basal sliding factor, and the geothermal heat flux). Either group of parameters can cause mass loss from the ice sheet to be high or low, given fixed values of the parameters in the other group. For example, a high ice positive degree-day factor might be associated with a low snow positive degree-day factor to produce the same amount of melt as a model run with more moderate values of both parameters. This interaction is bounded, however, because the maximum snow positive degree-day factor is much lower than the maximum value for ice; also, at the peak of the ablation season, there is no snow left on the lower parts of the ice sheet, so the ice positive degree-day factor dominates over part of the year. Similarly, the same ice velocities can be produced by either a high flow enhancement factor and a low basal sliding factor, or the reverse. Basal sliding can be a much faster process than ice flow, so this parameter interaction is also bounded. However, basal sliding operates only where the bed is thawed, and the geothermal heat flux likely controls the fraction of the bed that is above the pressure melting point.

The relatively small number of design points in the ensemble presented by Applegate et al. (2012) hinders mapping of the interactions among parameters over their fivedimensional space. Coherent mapping requires many more design points, but performing these additional runs with the full ice sheet model is impractical because of the model's high computational cost. This problem suggests a need for a computationally efficient emulator to fill the gaps in parameter space between the existing model runs.

\section{Methods}

As described above, our goals are (1) to present a method for quantifying the agreement between ice sheet model output and observations that incorporates spatial information, (2) to characterize the interactions among input parameters, and (3) to produce illustrative projections of sea level rise from the Greenland Ice Sheet based on synthetic data. In this section, we provide an outline of our methods for achieving these goals; fuller descriptions appear in Chang et al. (2014) and in the Supplement.

We accomplish goal no. 1 through constructing a statistical model that results in a likelihood function. This statistical model compares ice sheet model output and observations to evaluate the plausibility of a vector of model input parameter values $\theta$ while accounting for systematic discrepancies between the model output and the observations. The likelihood function for the ice thickness observations, denoted by $Z$, is based on the additive model

$Z=Y(\theta)+\delta+\varepsilon$, 
where $Y(\theta)$ is the ice thickness output from the SICOPOLIS model at the vector of input parameter values $\theta, \delta$ is the discrepancy between model output and observations caused by structural problems in the model, and $\varepsilon$ is independently and identically distributed observational noise.

To achieve goal no. 2, we perform a "leave-one-out" perfect model experiment with a Gaussian process emulator, a computationally cheap surrogate for the full ice sheet model. As described above, the model output $Y(\theta)$ is available only at a relatively small number of points in parameter space, and therefore it is necessary to build an emulator that approximates the model output $Y(\theta)$ at any given $\theta$.

Direct emulation of the full two-dimensional ice thickness grid is prohibitively expensive, due to (i) the cost of performing operations on large covariance matrices (see the Supplement and Chang et al., 2014, for details) and (ii) the need to model spatial processes that contain many zeros, which poses non-trivial computational and inferential challenges. To mitigate these problems, we take the mean of each row in the ice thickness grid, thereby obtaining a 264-element vector of zonally averaged ice thicknesses for each ice sheet model run. We then apply principal component analysis to these mean ice thickness vectors. The magnitudes of the first 10 principal components suffice to recover the mean ice thickness vectors. Because the principal components are uncorrelated, we can construct a separate emulator for the magnitude of each principal component. Our emulator consists of all these independent Gaussian processes. Although our emulator operates in the principal component space, we can reconstruct the ice thickness profile that corresponds to the emulated principal components (see the Supplement). Note that our likelihood formulation automatically penalizes the components with lower explained variation.

Next, we train the emulator on all but one of the model runs. We refer to the output (specifically, the zonal mean ice thickness profile and the ice volume change projection) from this left-out model run as our "assumed truth". We examined the robustness of our methods by successively leaving out each model run in turn and repeating our analysis (see the Supplement).

Before using the mean ice thickness profile from our assumed-true model run in our perfect model experiment, we contaminate it with spatially correlated errors. These errors reflect the discrepancies that we would expect to see between model output and data in a "real" calibration experiment due to missing or parameterized processes in the model. In particular, we use spatially correlated errors with a moderate magnitude (standard deviation of $50 \mathrm{~m}$ ) and a large-scale spatial trend to represent a situation in which (i) the ice sheet model has reasonable skill in reproducing the observed spatial pattern of modern ice thickness and (ii) the discrepancy pattern is notably different from patterns generated by the ice sheet model and is therefore statistically identifiable (see the Supplement). Note that any probabilistic calibration method, including our approach, can be uninformative if condition (i) is violated, or subject to serious bias if condition (ii) is violated.

We then use Markov chain Monte Carlo (MCMC) to estimate the joint posterior probability distribution over the five-dimensional input parameter space. MCMC is a wellestablished (Hastings, 1970), but complex, statistical technique; Brooks et al. (2011) provide a book-length treatment. Briefly, the Metropolis-Hastings algorithm used in MCMC constructs a sequence of parameter combinations, each of which is chosen randomly from the region of parameter space surrounding the last point. Candidate parameter combinations are accepted if the posterior probability of the new point is greater than at the previous one, or with a certain probability determined by the Metropolis-Hastings acceptance ratio otherwise. If the candidate point is rejected, another candidate point is chosen at random according to a proposal distribution. Consistent with McNeall et al. (2013), we match the emulator estimates to assumed-true model output instead of observed ice thickness values (Bamber et al., 2001, 2013) because a perfect model experiment is more suitable to achieve our main objectives, studying and demonstrating the performance of our probabilistic calibration method. The candidate points that are retained by the MCMC algorithm approximate the posterior probability distribution of the input parameter space. The candidate points from this algorithm therefore reflect various characteristics of the posterior distribution, including the marginal distributions of each of the parameters separately and their joint distributions. Hence, we can use MCMC to summarize what we have learned about the parameters from the model and observations while accounting for various uncertainties and prior information.

Finally, to achieve goal no. 3, we use a separate Gaussian process emulator to interpolate between the ice volume change projections from all the model runs in the original ensemble (Applegate et al., 2012), except the assumed-true realization. When applied to the sample of the model input parameters that we obtained from Markov chain Monte Carlo, this emulator yields a sample of ice volume changes, and thus sea level rise contributions, between 2005 and 2100. We then use kernel density estimation to compute the probability density of the projected sea level rise contributions. It should be noted that these projections are based on synthetic data (not real observations) and do not represent "real" projections of Greenland Ice Sheet mass loss over this century.

\section{Results}

Besides helping to diagnose interactions among ice sheet model parameters, our perfect model experiment allows us to test our overall procedure. We carry out several checks.

1. If the trained emulator is given the parameter settings from the left-out model realization, it should produce a close approximation to the actual output from that realization. 

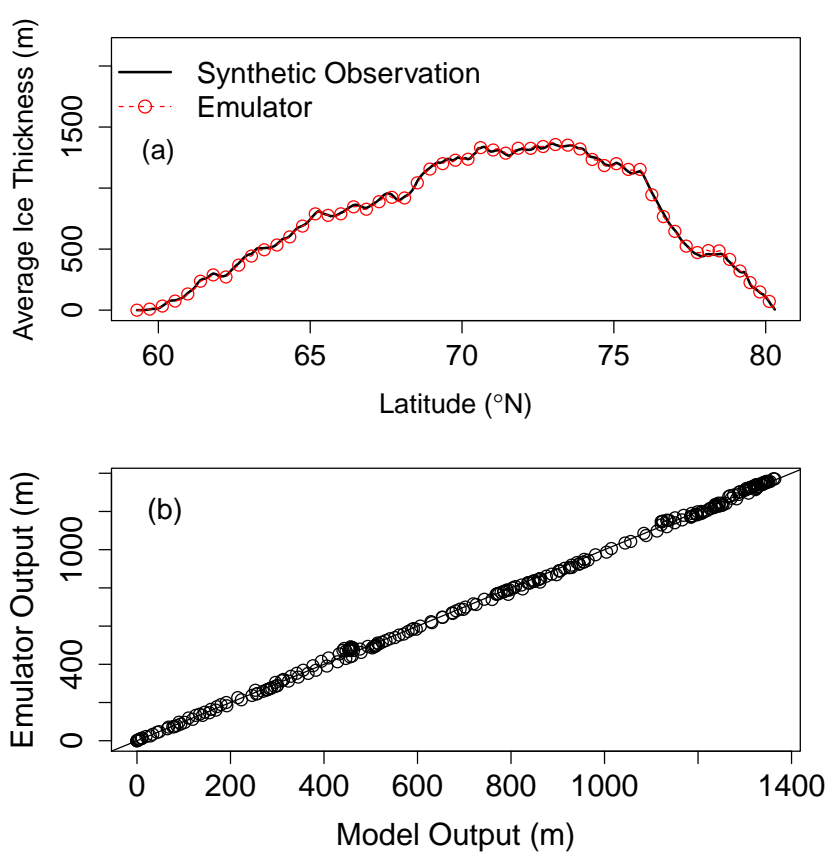

Figure 2. Comparison of zonal mean ice thickness transects from the assumed-true model run (\#67 from Applegate et al., 2012) and that generated by the trained emulator at the same parameter combination as used in the assumed-true model run. In the top panel, the assumed-true profile is shown by a solid black curve, and the emulator output is shown by a dashed red curve with circles. In the lower panel, each point stands for an individual latitude location. The red circles in the top panel fall almost exactly on top of the black curve, and the points in the lower panel fall almost exactly on a 1:1 line connecting the lower left and upper right corners of the plot. Thus, the emulator successfully recovers the ice thicknesses from an assumed-true model realization when trained on the other model runs from the same ensemble. See Fig. S4 in the Supplement for results for other assumed-true model realizations.

2. The maximum of the multidimensional posterior probability function from our Markov chain Monte Carlo analysis should lie close to the parameter settings from the left-out model realization.

3. The mode of the probability density function of ice loss projections should be close to the ice loss projection from the assumed-true model realization.

As detailed below, our methods pass all three of these checks.

Aggregating the ice thicknesses to their zonal means allows easy visual comparison of different emulator-estimated ice thickness vectors to the assumed-true model realization (black curve, Fig. 1). The emulator, as trained on 99 of the model realizations from the Applegate et al. (2012) ensemble, successfully recovers the ice thicknesses from the left-out model realization (Fig. 2) when given the parameter combination for that left-out model realization as input. Differences between the assumed-true and emulated zonally
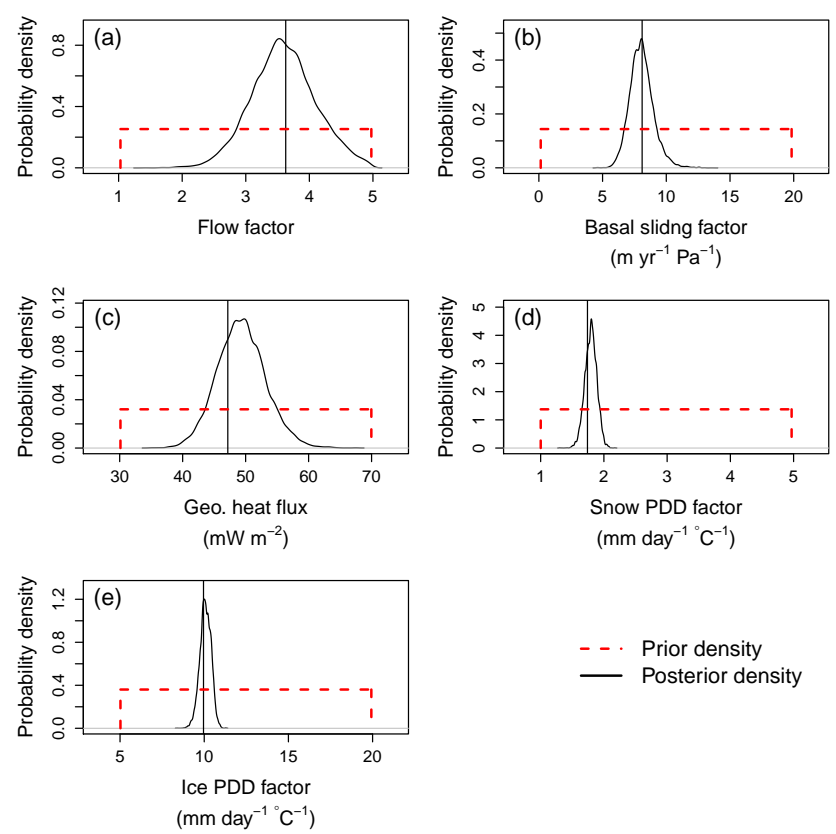

$\begin{array}{ll}\text { - } & \text { Prior density } \\ \text { - Posterior density }\end{array}$

Figure 3. Prior (dashed red curves) and posterior (solid black curves) probability density functions of each input parameter, assuming that all the other parameters are held fixed at their assumedtrue values. The vertical lines indicate the assumed-true values of the individual parameters. See Fig. S2 in the Supplement for the effect of excluding the discrepancy term ( $\delta$ in Eq. 1$)$ on the results.

averaged ice thickness vectors are minor. Thus, our methods pass check no. 1 , above.

Similarly, the conditional posterior density functions (Fig. 3) have maxima near the assumed-true parameter values. Parameter combinations yielding zonally averaged ice thickness curves that lie close to the assumed-true model realization (e.g., the red curve in Fig. 1) are more likely (more probable based on the posterior distribution) than those with curves that lie farther from the assumed-true values (blue and green curves in Fig. 1). We do not expect that the modes of the marginal posterior density functions (Fig. 4b) will fall exactly at the assumed-true parameter values because summing over one or more dimensions often moves the marginal mode away from the maximum of the multidimensional probability density function. In any case, the maximum posterior probability is close to the assumed-true parameter combination. Thus, our methods pass check no. 2, above. Some of the twodimensional marginal probability density functions (Fig. 4b) show multiple modes and bands of high probability extending across the two-dimensional fields; we discuss the significance of these features below.

For comparison, we also produced scatterplots of parameter combinations as projected onto two-dimensional slices through the five-dimensional parameter space (Fig. 4a), following Applegate et al. (2012, their Fig. 1). As in Applegate et al. (2012), the "successful" design points show no 
clustering around the assumed-true parameter values, except for the ice positive degree-day factor.

Our method also successfully recovers the ice volume loss produced by the assumed-true model realization (Fig. 5; see also Fig. S5 in the Supplement), reflected by the close correspondence between the mode of the probability density function produced by our methods and the vertical black line. Thus, our methods pass check no. 3, listed above. As previously noted, these projections are based on synthetic data; they are not "real" projections of Greenland Ice Sheet mass loss. For comparison, we also applied the windowing approach used by Applegate et al. (2012) to the model runs and the synthetic observation. The $95 \%$ probable interval produced by our methods is much smaller than that estimated by computing the 2.5 th and the 97.5 th percentiles of the synthetic volume change values selected by the $10 \%$ volume filter used in Applegate et al. (2012). This reflects the utility of spatial information and our probabilistic calibration approach in reducing projection uncertainties compared to the windowing approach in Applegate et al. (2012).

The prior density for the ice volume loss was constructed by assuming that all 99 design points used to train our emulator are equally likely. Interestingly, a uniform prior for the input parameters results in a skewed and multimodal prior distribution for the volume loss, indicating that the function that maps input parameters to projected ice volume changes is highly non-linear and not smooth. These characteristics also cause a small offset between the assumed-true projection and the mode of the posterior density. The marginal plots for the volume loss projection surfaces are shown in Fig. S3 in the Supplement.

\section{Discussion}

As explained above, our goals for this work were to identify an objective function for matching ice sheet models to spatially distributed data (especially ice thicknesses), map interactions among model input parameters, and develop methods for projecting future ice sheet mass loss, with wellcharacterized uncertainties. We demonstrated that our emulator reproduces a vector of zonally averaged ice thicknesses from a given model run when trained on other members from the same ensemble (Fig. 2). We further showed that the emulator can recover the appropriate parameter combinations for an assumed-true model realization in a perfect model experiment (Figs. 3, 4b). Finally, we produced illustrative projections of Greenland Ice Sheet mass loss based on synthetic data (Fig. 5; see also Fig. S5 in the Supplement). As noted above, our projections are for illustration only and do not represent "real" projections of future Greenland Ice Sheet mass loss.

The utility of our approach becomes clear in comparing the marginal posterior probability density functions (Fig. 4b) and projections (red probability density function and box plot in Fig. 5) to results from simpler methods (Fig. 4a; blue box plot in Fig. 5; Applegate et al., 2012). In Fig. 4b, there are distinct modes in the marginal densities, indicating regions of parameter space that are more consistent with the assumed truth. These modes are absent in the simpler graphic (Fig. 4a). Similarly, the $95 \%$ prediction interval of sea level rise contributions is narrower using our methods than if a simple windowing approach is applied (Fig. 5). Our results also show the importance of including the discrepancy term ( $\delta$ in Eq. 1) for recovering the appropriate parameter settings in our perfect model experiments (Fig. S2 in the Supplement). If we leave this discrepancy term out, the marginal posterior density functions for each parameter clearly miss the true values.

The parameter interactions identified in this experiment are generally consistent with intuition (see Sect. 1.2 for descriptions of anticipated parameter interactions). Figure 4 shows inclined bands of high marginal posterior probability in the ice positive degree-day factor vs. snow positive degreeday factor, geothermal heat flux vs. ice flow factor, and basal sliding factor vs. flow factor panels. As expected, there are tradeoffs among each of these parameter pairs; for example, a low ice positive degree-day factor must be combined with a high snow positive degree-day factor to produce a reasonable match to the assumed truth. Somewhat surprisingly, the tradeoff between the geothermal heat flux and the ice flow factor is much stronger than that between the geothermal heat flux and the basal sliding factor. The geothermal heat flux affects both ice deformation (which is temperature-sensitive) and basal sliding (which operates only where there is liquid water at the ice-bed interface). We hypothesize that the geothermal heat flux has a stronger effect on ice flow than basal sliding because ice deformation happens over a much larger fraction of the ice sheet's basal area than does sliding.

Multiple modes appear in the two-dimensional marginal density plots (Fig. 4), implying that standard methods for tuning of ice sheet models may converge to "non-optimal" parameter combinations. Ice sheet models are commonly tuned by manually adjusting one parameter at a time until the simulated modern ice sheet resembles the real one (e.g., Greve et al., 2011). This procedure is an informal variant of so-called gradient descent methods, which search for optimal matches between models and data by moving down a continuous surface defined by the model's input parameters, the objective function, and the data. If the surface has multiple "peaks" (i.e., regions of parameter space that are more plausible, given observations, than their surroundings), gradient descent methods can converge to a point which produces a better match to the data than any adjacent point, but is nevertheless far from the "best" parameter combination.

This problem may partly explain the wide variation in projections of sea level rise from the ice sheets, as made with state-of-the-art ice sheet models. Two recent intercomparison projects, Sea-level Response to Ice Sheet Evolution (SeaRISE) and ice2sea (Bindschadler et al., 2013; Shannon 

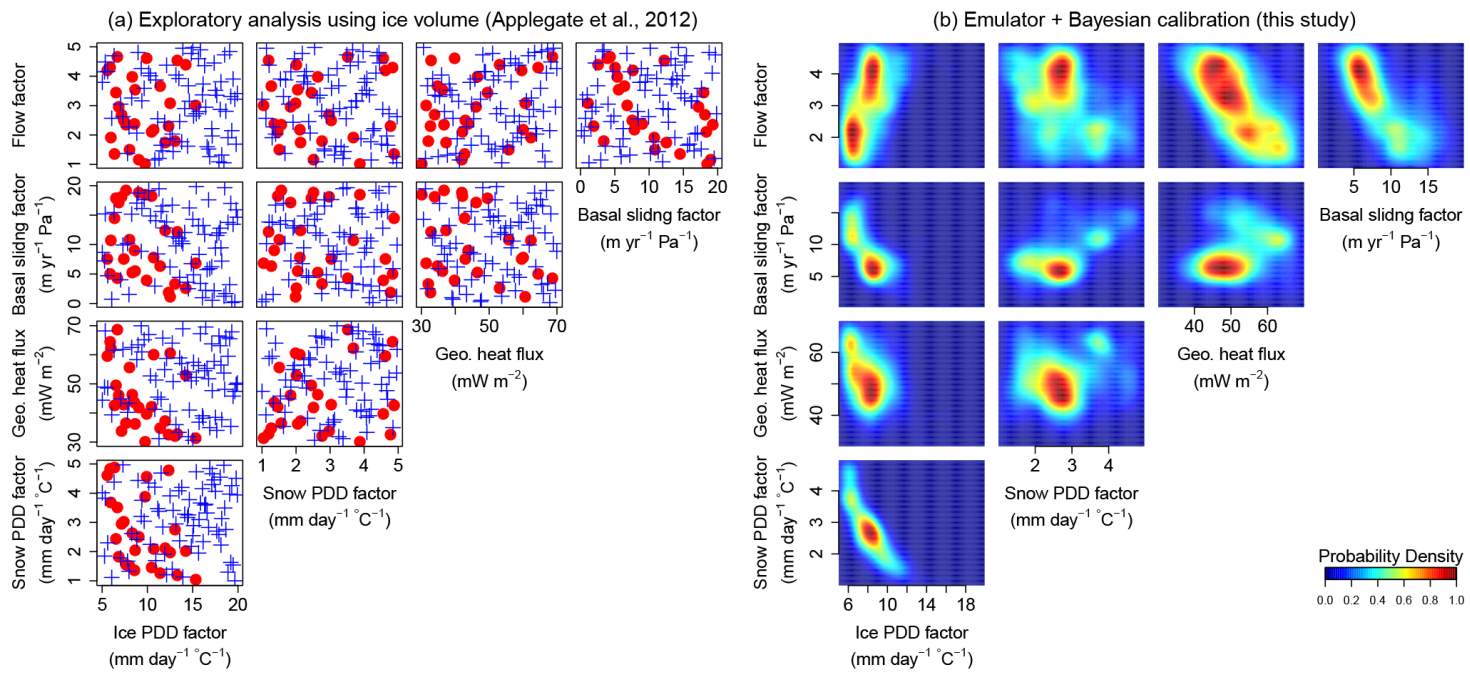

Figure 4. Comparison between an exploratory data analysis, following Applegate et al. (2012), and the results of our probabilistic calibration. Scatterplots of parameter settings used to train the emulator, as projected onto two-dimensional marginal spaces (a). Red dots are parameter settings resulting in simulated modern ice volumes within $10 \%$ of the synthetic truth (model run \#67 of Applegate et al., 2012); blue crosses are parameter settings that yield ice volumes more than $10 \%$ larger or smaller than the synthetic truth. Two-dimensional marginal posterior densities of all pairs of input parameters (b). Several of the marginal posterior density maps show inclined bands of higher probability, indicating interactions among parameters; other panels show multiple modes, representing potential "traps" for tuning of ice sheet models using simpler methods. See text for discussion.

et al., 2013; Edwards et al., 2014a) used a variety of ice sheet models to project future ice sheet contributions to sea level rise. The two projects used different groups of ice sheet models and different methods for spinning up the participating models. The results of one of these projects shows strong divergence among the results from different models (Bindschadler et al., 2013), whereas the other project's projections agree more closely (Shannon et al., 2013; Edwards et al., 2014a). The multiple modes in our posterior twodimensional density plots (Fig. 4) suggest that some of the divergence among models, for example in the SeaRISE project (Bindschadler et al., 2013), may be due to differences in model tuning: even if the models had similar structures and reproduced the modern ice sheet topography and ice thicknesses equally well, we would still expect their future projections to diverge because of differences in input parameter choice.

Our leave-one-out cross-validation shows that the results presented here are consistent across all 100 synthetic truths. The prediction interval for the ice volume changes in Fig. 5 achieves the nominal coverage when the synthetic truth yields a modern ice volume that is close to the observed modern ice volume (Fig. S5 in the Supplement). The parameter interactions shown in Fig. 4 are also consistent across the majority of the synthetic truths (Fig. S6 in the Supplement).

\subsection{Caution and future directions}

In this paper, we specifically avoid giving "real" projections of future Greenland Ice Sheet volume change, for two reasons. First, we match only a two-dimensional profile of zonally averaged ice thicknesses from an assumed-true model run, rather than the two-dimensional grid of observed ice thicknesses (Bamber et al., 2001, 2013; see also McNeall et al., 2013). Second, the ensemble of ice sheet model runs (Applegate et al., 2012) that we use to calibrate our emulator has several important limitations, including the relative simplicity of the model used to generate the ensemble and the synthetic climate scenario used to drive the ensemble members into the future. Most importantly, this ensemble's simulated modern ice sheets are generally too thick in the southern part of Greenland and too thin in the northern part of the island (Applegate et al., 2012, their Fig. 7); other studies that allow the ice sheet surface to evolve freely have noted similar difficulties in reproducing the modern ice sheet (e.g., Stone et al., 2010; Greve et al., 2011; Nowicki et al., 2013, their Fig. 2; cf. Edwards et al., 2014a). The long-term goal of this work is to compare ice sheet model runs to actual data, thereby resulting in probabilistic projections of future ice sheet mass loss. To achieve this goal, we plan to expand our method to treat the full, two-dimensional ice thickness grid and take advantage of other spatially distributed data sets (e.g., surface velocities; Joughin et al., 2010) and to generate new ice sheet model ensembles that overcome the limitations explained above.

\section{Conclusions}

In this paper, we presented an approach for probabilistic calibration of ice sheet models using spatially resolved ice 


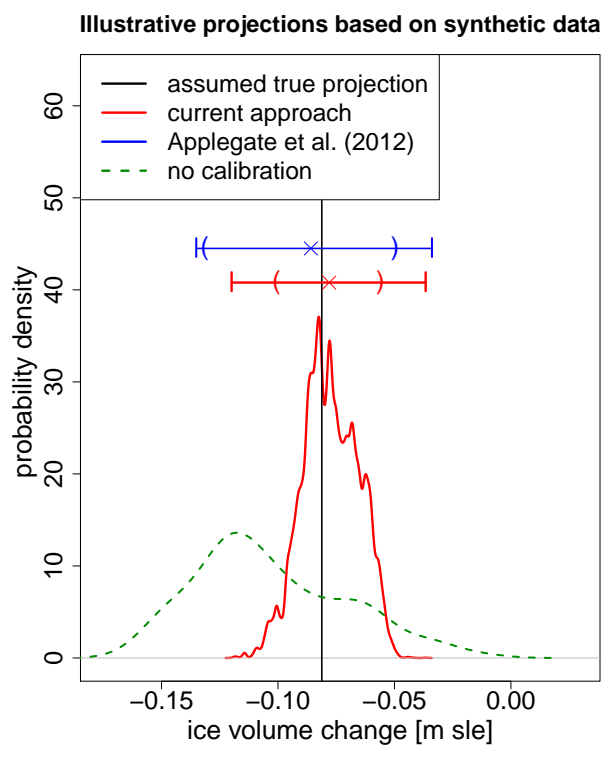

Figure 5. Illustrative (not "real") ice volume change projections between 2005 and 2100, based on three different methods: (i) the prior density of the input parameters (dashed green line); (ii) parameter settings that pass the $10 \%$ ice volume filter used by Applegate et al. (2012) (solid blue line); and (iii) the posterior density computed by our calibration approach (solid red line). The vertical line shows the ice volume change projection for the assumed-true parameter setting. The horizontal lines and the parentheses on them represent the range and the $95 \%$ prediction intervals, respectively; the crosses indicate the median projection from each method. The width of the $95 \%$ projection interval from our methods is narrower than if simpler methods are applied (blue box plot; Applegate et al., 2012). Similar results are obtained if different model runs from the ensemble are left out (see Fig. S5 in the Supplement). See text for discussion. The notation $\mathrm{m}$ sle stands for meters of sea level equivalent.

thickness information. Specifically, we constructed a probability model for assigning posterior probabilities to individual ice sheet model runs, and we used a Gaussian process emulator to interpolate between existing ice sheet model simulations. We reduced the dimensionality of the emulation problem by reducing profiles of mean ice thicknesses to their principal components. Finally, we showed how the posterior probabilities from the model calibration exercise can be used to make projections of future sea level rise from the ice sheets. In a perfect model experiment where the "true" parameter settings and future contributions of the ice sheet to sea level rise are known, our methods successfully recovered these values. The posterior probability density function that resulted from this experiment shows tradeoffs among parameters and multiple modes. The tradeoffs are consistent with physical expectations, whereas the multiple modes may indicate that commonly applied methods for tuning ice sheet models can lead to calibration errors.

\section{The Supplement related to this article is available online at doi:10.5194/gmd-7-1933-2014-supplement.}

\section{Author Contributions}

W. Chang designed the emulator, carried out the analyses, and wrote the first draft of the Supplement. P. J. Applegate wrote the first draft of the body text and supplied the previously published ice sheet model runs (available online at http://bolin.su.se/data/Applegate-2011). W. Chang, P. J. Applegate, M. Haran, and K. Keller jointly designed the research and edited the paper text.

Acknowledgements. We thank R. Greve for distributing his ice sheet model SICOPOLIS freely on the Web (http://sicopolis.greveweb.net/) and N. Kirchner for help in setting up and using the model. R. Alley and D. Pollard provided helpful comments on a draft of the manuscript. This work was partially supported by the US Department of Energy, Office of Science, Biological and Environmental Research Program, Integrated Assessment Program, grant no. DE-SC0005171; by the US National Science Foundation through the Network for Sustainable Climate Risk Management (SCRiM) under NSF cooperative agreement GEO-1240507; and by the Penn State Center for Climate Risk Management. Any opinions, findings, and conclusions expressed in this work are those of the authors, and do not necessarily reflect the views of the National Science Foundation or the Department of Energy.

Edited by: I. Rutt

\section{References}

Alexander, L. V., Allen, S. K., Bindoff, N. L., Bron, F. M., Church, J. A., Cubasch, U., Emori, S., Forster, P., Friedlingstein, P., Gillett, N., Gregory, J. M., Hartmann, D. L., Jansen, E., Kirtman, B., Knutti, R., Kanikicharla, K. K., Lemke, P., Marotzke, J., Masson-Delmotte, V., Meehl, G. A., Mokhov, I. I., Piao, S., Plattner, G. K., Dahe, Q., Ramaswamy, V., Randall, D., Rhein, M., Rojas, M., Sabine, C., Shindell, D., Stocker, T. F., Talley, L. D., Vaughan, D. G., and Xie, S. P.: Climate Change 2013: The Physical Science Basis: Contribution of Working Group I to the Fifth Assessment Report of the Intergovernmental Panel on Climate Change, IPCC, Cambridge University Press, Cambridge, 2013.

Alley, R. B., Andrews, J. T., Brigham-Grette, J., Clarke, G. K. C., Cuffey, K. M., Fitzpatrick, J. J., Funder, S., Marshall, S. J., Miller, G. H., Mitrovica, J. X., Muhs, D. R., Otto-Bliesner, B. L., Polyak, L., and White, J. W. C.: History of the Greenland Ice Sheet: paleoclimatic insights, Quaternary Sci. Rev., 29, 17281756, 2010.

Applegate, P. J., Kirchner, N., Stone, E. J., Keller, K., and Greve, R.: An assessment of key model parametric uncertainties in projections of Greenland Ice Sheet behavior, The Cryosphere, 6, 589606, doi:10.5194/tc-6-589-2012, 2012.

Bamber, J. L., Layberry, R. L., and Gogineni, S. P.: A new ice thickness and bed data set for the Greenland Ice Sheet 1. Measure- 
ment, data reduction, and errors, J. Geophys. Res., 106, 3377333780, 2001.

Bamber, J. L., Griggs, J. A., Hurkmans, R. T. W. L., Dowdeswell, J. A., Gogineni, S. P., Howat, I., Mouginot, J., Paden, J., Palmer, S., Rignot, E., and Steinhage, D.: A new bed elevation dataset for Greenland, The Cryosphere, 7, 499-510, doi:10.5194/tc-7499-2013, 2013.

Bindschadler, R. A., Nowicki, S., Abe-Ouchi, A., Aschwanden, A., Choi, H., Fastook, J.,Granzow, G., Greve, R., Gutowski, G., Herzfeld, U., Jackson, C., Johnson, J., Khroulev, C., Levermann, A., Lipscomb, W. H., Martin, M. A., Morlighem, M., Parizek, B. R., Pollard, D., Price, S. F., Ren, D., Saito, F., Sato, T., Seddik, H., Seroussi, H., Takahashi, K., Walker, R., and Wang, W. L.: Icesheet model sensitivities to environmental forcing and their use in projecting future sea level (the SeaRise project), J. Glaciol., 59, 195-224, 2013.

Born, A. and Nisancioglu, K. H.: Melting of Northern Greenland during the last interglaciation, The Cryosphere, 6, 1239-1250, doi:10.5194/tc-6-1239-2012, 2012.

Braithwaite, R. J.: Positive degree-day factors for ablation on the Greenland ice sheet studied by energy-balance modelling, J. Glaciol., 41, 153-160, 1995.

Brooks, S., Gelman, A., Jones, G., and Meng, X.-L. (Eds.): Handbook of Markov Chain Monte Carlo, Chapman and Hall/CRC, 619 pp., 2011.

Calov, R. and Greve, R.: A semi-analytical solution for the positive degree-day model with stochastic temperature variations, J. Glaciol., 51, 173-175, 2005.

Chang, W., Haran, M., Olson, R., and Keller, K.: Fast dimensionreduced climate model calibration, Ann. Appl. Stat., 8, 649-673, 2014.

Church, J. A. and White, N. J.: A 20th century acceleration in global sea-level rise, Geophys. Res. Lett., 33, L01602, doi:10.1029/2005GL024826, 2006.

Dansgaard, W., Johnsen, S. J., Clausen, H. B., Dahl-Jensen, D., Gundestrup, N. S., Hammer, C. U., Hvidberg, C. S., Steffensen, J. P., Sveinbjörnsdottir, A. E., Jouzel, J., and Bond, G.: Evidence for general instability of past climate from a $250-\mathrm{kyr}$ ice core record, Nature, 364, 218-220, 1993.

Edwards, T. L., Fettweis, X., Gagliardini, O., Gillet-Chaulet, F., Goelzer, H., Gregory, J. M., Hoffman, M., Huybrechts, P., Payne, A. J., Perego, M., Price, S., Quiquet, A., and Ritz, C.: Effect of uncertainty in surface mass balance-elevation feedback on projections of the future sea level contribution of the Greenland ice sheet, The Cryosphere, 8, 195-208, doi:10.5194/tc-8-195-2014, 2014a.

Edwards, T. L., Fettweis, X., Gagliardini, O., Gillet-Chaulet, F., Goelzer, H., Gregory, J. M., Hoffman, M., Huybrechts, P., Payne, A. J., Perego, M., Price, S., Quiquet, A., and Ritz, C.: Probabilistic parameterisation of the surface mass balance-elevation feedback in regional climate model simulations of the Greenland ice sheet, The Cryosphere, 8, 181-194, doi:10.5194/tc-8-181-2014, 2014b.

Fitzgerald, P. W., Bamber, J. L., Ridley, J. K., and Rougier, J. C.: Exploration of parametric uncertainty in a surface mass balance model applied to the Greenland ice sheet, J. Geophys. Res., 117, F01021, doi:10.1029/2011JF002067, 2012.

Fyke, J. G., Weaver, A. J., Pollard, D., Eby, M., Carter, L., and Mackintosh, A.: A new coupled ice sheet/climate model: de- scription and sensitivity to model physics under Eemian, Last Glacial Maximum, late Holocene and modern climate conditions, Geosci. Model Dev., 4, 117-136, doi:10.5194/gmd-4-1172011, 2011.

Gillet-Chaulet, F., Gagliardini, O., Seddik, H., Nodet, M., Durand, G., Ritz, C., Zwinger, T., Greve, R., and Vaughan, D. G.: Greenland ice sheet contribution to sea-level rise from a new-generation ice-sheet model, The Cryosphere, 6, 1561-1576, doi:10.5194/tc-6-1561-2012, 2012.

Gladstone, R. M., Lee, V., Rougier, J., Payne, A. J., Hellmer, H., Le Brocq, A., Shepherd, A., Edwards, T. L., Gregory, J., and Cornford, S. L.: Calibrated prediction of Pine Island Glacier retreat during the 21st and 22nd centuries with a coupled flowline model, Earth Planet. Sc. Lett., 333-334, 191-199, doi:10.1016/j.eps1.2012.04.022, 2012.

Goelzer, H., Huybrechts, P., Fürst, J. J., Nick, F. M., Andersen, M. L., Edwards, T. L., Fettweis, X., Payne, A. J., and Shannon, S.: Sensitivity of Greenland ice sheet projections to model formulations, J. Glaciol., 59, 1-17, doi:10.3189/2013JoG12J182, 2013.

Greve, R.: Application of a polythermal three-dimensional ice sheet model to the Greenland Ice Sheet: response to steady-state and transient climate scenarios, J. Climate, 10, 901-918, 1997.

Greve, R. and Otsu, S.: The effect of the north-east ice stream on the Greenland ice sheet in changing climates, The Cryosphere Discuss., 1, 41-76, doi:10.5194/tcd-1-41-2007, 2007.

Greve, R., Saito, F., and Abe-Ouchi, A.: Initial results of the SeaRISE numerical experiments with the models SICOPOLIS and IcIES for the Greenland Ice Sheet, Ann. Glaciol., 52, 23-30, 2011.

Hastings, W. K.: Monte Carlo sampling methods using Markov chains and their applications, Biometrika, 57, 97-109, 1970.

Hebeler, F., Purves, R. S., and Jamieson, S. S. R.: The impact of parametric uncertainty and topographic error in ice-sheet modelling, J. Glaciol., 54, 899-919, 2008.

Heimbach, P. and Bugnion, V.: Greenland ice-sheet volume sensitivity to basal, surface and initial conditions derived from an adjoint model, Ann. Glaciol., 50, 67-80, 2009.

Huybrechts, P.: Sea-level changes at the LGM from ice-dynamic reconstructions of the Greenland and Antarctic ice sheets during the glacial period, Quaternary Sci. Rev., 21, 203-231, 2002.

Imbrie, J., Hays, J. D., Martinson, D. G., McIntyre, A., Mix, A. C., Morley, J. J., Pisias, N. G., Prell, W. L., and Shackleton, N. J.: The orbital theory of Pleistocene climate: support from a revised chronology of the marine $\delta^{18} \mathrm{O}$ record, in: Milankovitch and climate: understanding the response to astronomical forcing, Part 1, edited by: Berger, A. J., Imbrie, J., Hays, J., Kukla, G., and Saltzman, B., D. Reidel Publishing Co., Dordrecht, 269-305, 1984.

Jevrejeva, S., Moore, J. C., Grinsted, A., and Woodworth, P. L.: Recent global sea level acceleration started over 200 years ago?, Geophys. Res. Lett., 35, L08715, doi:10.1029/2008GL033611, 2008.

Johnsen, S. J., Clausen, H. B., Dansgaard, W., Gundestrup, N. S., Hammer, C. U., Andersen, U., Andersen, K. K., Hvidberg, C. S., Dahl-Jensen, D., Steffensen, J. P., Shoji, H., Sveinbjörnsdottir, A. E., White, J., Jouzel, J., and Fisher, D.: The $\delta^{18} \mathrm{O}$ record along the Greenland Ice Core project deep ice core and the problem of possible Eemian climatic instability, J. Geophys. Res., 102, 26397-26410, 1997. 
Joughin, I., Smith, B. E., Howat, I. M., Scambos, T., and Moon, T.: Greenland flow variability from ice-sheet-wide velocity mapping, J. Glaciol., 56, 415-430, 2010.

Kennedy, M. C. and O'Hagan, A.: Bayesian calibration of computer models, J. Roy. Stat. Soc. B Met., 63, 425-464, 2001.

Kirchner, N., Hutter, K., Jakobsson, M., and Gyllencreutz, R.: Capabilities and limitations of numerical ice sheet models: a discussion for Earth-scientists and modelers, Quaternary Sci. Rev., 30, 3691-3704, 2011.

Lemke, P., Ren, J., Alley, R. B., Allison, I., Carrasco, J., Flato, G., Fujii, Y., Kaser, G., Mote, P., Thomas, R. H., and Zhang, T.: Observations: changes in snow, ice, and frozen ground, edited by: Solomon, S., Qin, D., Manning, M., Chen, Z., Marquis, M., Averyt, K. B., Tignor, M., and Miller, H. L., Cambridge University Press, Cambridge, 2007.

Lempert, R., Sriver, R. L., and Keller, K.: Characterizing uncertain sea level rise projections to support investment decisions, California Energy Commission Report CEC-500-2012-056, 2012.

Lenton, T. M., Held, H., Kriegler, E., Hall, J. W., Lucht, W., Rahmstorf, S., and Schnellnhuber, H. J.: Tipping elements in the Earth's climate system, P. Natl. Acad. Sci. USA, 105, 17861793, 2008.

Little, C. M., Oppenheimer, M., Urban, N. M.: Upper bounds on twenty-first-century Antarctic ice loss assessed using a probabilistic framework, Nature Climate Change 3, 654-659, doi:10.1038/nclimate1845, 2013.

McKay, M. D., Beckman, R. J., and Conover, W. J.: A comparison of three methods for selecting values of input variables in the analysis of output from a computer code, Technometrics, 21, 239-245, 1979.

McNeall, D. J., Challenor, P. G., Gattiker, J. R., and Stone, E. J.: The potential of an observational data set for calibration of a computationally expensive computer model, Geosci. Model Dev., 6, 1715-1728, doi:10.5194/gmd-6-1715-2013, 2013.

Meehl, G. A., Stocker, T. F., Collins, W. D., Friedlingstein, P., Gaye, A. T., Gregory, J. M., Kitoh, A., Knutti, R., Murphy, J. M., Noda, A., Raper, S. C. B., Watterson, I. G., Weaver, A. J., and Zhao, Z.-C.: Global climate projections, edited by: Solomon, S., Qin, D., Manning, M., Chen, Z., Marquis, M., Averyt, K. B., Tignor, M., and Miller, H. L., Cambridge University Press, Cambridge, 2007.

Nowicki, S., Bindschadler, R. A., Abe-Ouchi, A., Aschwanden, A., Bueler, E., Choi, H., Fastook, J., Granzow, G., Greve, R., Gutowski, G., Herzfeld, U., Jackson, C., Johnson, J., Khroulev, C., Larour, E., Levermann, A., Lipscomb, W. H., Martin, M. A., Morlighem, M., Parizek, B. R., Pollard, D., Price, S. F., Ren, D., Rignot, E., Saito, F., Sato, T., Seddik, H., Seroussi, H., Takahashi, K., Walker, R., and Wang, W. L.: Insights into spatial sensitivities of ice mass response to environmental change from the SeaRISE ice sheet modeling project II: Greenland, J. Geophys. Res.-Earth, 118, 1025-1044, doi:10.1002/jgrf.20076, 2013.
Pollard, D. and DeConto, R. M.: A simple inverse method for the distribution of basal sliding coefficients under ice sheets, applied to Antarctica, The Cryosphere, 6, 953-971, doi:10.5194/tc-6953-2012, 2012.

Quiquet, A., Punge, H. J., Ritz, C., Fettweis, X., Gallée, H., Kageyama, M., Krinner, G., Salas y Mélia, D., and Sjolte, J.: Sensitivity of a Greenland ice sheet model to atmospheric forcing fields, The Cryosphere, 6, 999-1018, doi:10.5194/tc-6-9992012, 2012.

Ritz, C., Fabre, A., and Letreguilly, A.: Sensitivity of a Greenland Ice Sheet model to ice flow and ablation parameters: consequences for the evolution through the last climatic cycle, Clim. Dynam., 13, 11-24, 1997.

Robinson, A., Calov, R., and Ganopolski, A.: An efficient regional energy-moisture balance model for simulation of the Greenland Ice Sheet response to climate change, The Cryosphere, 4, 129144, doi:10.5194/tc-4-129-2010, 2010.

Rutt, I. C., Hagdorn, M., Hulton, N. R. J., and Payne, A. J.: The Glimmer community ice-sheet model, J. Geophys. Res.-Earth, 114, F02004, doi:10.1029/2008JF001015, 2009.

Sacks, J., Welch, W. J., Mitchell, T. J., and Wynn, H. P.: Design and analysis of computer experiments (with discussion), J. Stat. Sci., 4, 409-423, 1989.

Seddik, H., Greve, R., Zwinger, T., Gillet-Chaulet, F., and Gagliardini, O.: Simulations of the Greenland ice sheet 100 years into the future with the full Stokes model Elmer/Ice, J. Glaciol., 58, 427-440, 2012.

Shannon, S. R., Payne, A. J., Bartholomew, I. D., van den Broeke, M. R., Edwards, T. L., Fettweis, X., Gagliardini, O., GilletChaulet, F., Goelzer, H., Hoffman, M. J., Huybrechts, P., Mair, D. W. F., Nienow, P., Perego, M., Price, S. F., Smeets, C. J. P. P., Sole, A. J., van de Wal, R. S. W., and Zwinger, T.: Enhanced basal lubrication and the contribution of the Greenland ice sheet to future sea-level rise, P. Natl. Acad. Sci., 110, 1-4, doi:10.1073/pnas.1212647110, 2013.

Stone, E. J., Lunt, D. J., Rutt, I. C., and Hanna, E.: Investigating the sensitivity of numerical model simulations of the modern state of the Greenland ice-sheet and its future response to climate change, The Cryosphere, 4, 397-417, doi:10.5194/tc-4-397-2010, 2010.

Urban, N. M. and Fricker, T. E.: A comparison of Latin hypercube and grid ensemble designs for the multivariate emulation of an Earth system model, Comput. Geosci., 36, 746-755, 2010.

van der Berg, W. J., van den Broeke, M., Ettema, J., van Meijgaard, E., and Kaspar, F.: Significant contribution of insolation to Eemian melting of the Greenland ice sheet, Nat. Geosci., 4, 679-683, 2011.

Vizcaino, M., Mikolajewicz, U., Jungclaus, J., and Schurgers, G.: Climate modification by future ice sheet changes and consequences for ice sheet mass balance, Clim. Dynam., 34, 301-324, 2010 . 